\title{
Protection of W7-X diagnostics from radiation heat loads
}

\author{
André Carls;, Matthias Köppen, Joris Fellinger, Felix Schauer \\ Max Planck Institute for Plasma Physics, EURATOM Association, Wendelsteinstr. 1, 17491 Greifswald, Germany
}

\begin{abstract}
Wendelstein 7-X (W7-X), a modular advanced stellarator, is presently under construction at the Max Planck Institute for Plasma Physics in Greifswald. Part of the inner plasma vessel (PV) surface is covered by graphite tiles which are bolted onto water-cooled $\mathrm{CuCrZr}$ heat sink plates. This so-called heat shield shall protect in-vessel components and the PV wall from plasma-edge-radiation and convective heat loads. Numerous diagnostics (e.g. Diamagnetic loops, Rogowski coils, etc.) are located in between the heat shield and plasma vessel wall. They are loaded by thermal radiation from the hot heat shield backside, stray radiation from the electron cyclotron resonance heating $(\mathrm{ECRH})$, and plasma radiation through remaining gaps between the tiles. In order to keep the temperatures of the diagnostics within their specified limits, additional shielding is required. The paper presents the design of such a shielding for the diamagnetic loops and Rogowski coils. Several options of copper shields and loosely attached Sigraflex ${ }^{\circledR}$-layers, and combinations thereof, are compared with respect to their abilities to reduce the temperatures of the sensitive parts of the diagnostics. To increase the confidence in the results, a sensitivity study with widely varying radiative material properties has been carried out. The advantages and disadvantages of the potential solutions are discussed. As a result two copper shield variants which also reduce the load onto the plasma vessel are presented.
\end{abstract}

${ }^{*}$ corresponding author 


\section{Introduction}

The W7-X plasma vessel and diagnostics are protected by the heat shield or first wall, consisting of graphite tiles mounted on $\mathrm{CuCrZr}$ heat sinks (see Figure 2). The thermal load on the first wall was initially assumed to be about $200 \ldots 300 \mathrm{~kW} \cdot \mathrm{m}^{-2}[1,2]$. Later studies showed that in spatially limited regions loads on the first wall attain up to $500 \mathrm{~kW} \cdot \mathrm{m}^{-2}$. The water cooled heat sinks remove only part of the thermal energy from the graphite tiles. Their hot backsides emit the remaining heat to the plasma vessel, intermediary components and diagnostics, as shown in section (A) of Figure 3. This heat load is increased by the homogeneously dirstibuted ECRH stray radiation. Mock-up tests of diagnostics showed that the W7-X ECRH design load of $50 \mathrm{~kW} \cdot \mathrm{m}^{-2}$ generated temperatures close to or above $250{ }^{\circ} \mathrm{C}$ for certain diagnostics in the Microwave Stray Radiation Loading Facility (MISTRAL) [3]. This is a hazardous situation due to the temperature limit of $250{ }^{\circ} \mathrm{C}$ for diagnostics with Kapton ${ }^{\circledR}$ insulated wires. The heat flux on the plasma vessel reaches up to $15 \mathrm{~kW} \cdot \mathrm{m}^{-2}$ which significantly exceeds the design value of about $2 \mathrm{~kW} \cdot \mathrm{m}^{-2}[6]$ (see Figure 1). The paper presents shielding options to reduce the load on the plasma vessel and diagnostics. First a rough estimate is performed to choose a basic shield concept which is developed and analysed in the consecutive sections. Two shield variants are shown to be suitable to reduce the loads on diagnostics and plasma vessel to acceptable values.

\section{Choice of shield concept}

Heat load reduction can be achieved by installing a radiation heat shield behind the first wall and/or by reduction of ECRH heat fluxes with help of absorbing coatings. Last point is a discussed option, but the application seems not to be practical.

Thus only thermal radiation shields were considered: extension of the Sigraflex ${ }^{\circledR}$-layer between graphite and $\mathrm{CuCrZr}$, and insertion of additional reflecting $\mathrm{Cu}$-sheets as shown in Figure 3. An estimation for radiation loads through such a shield in

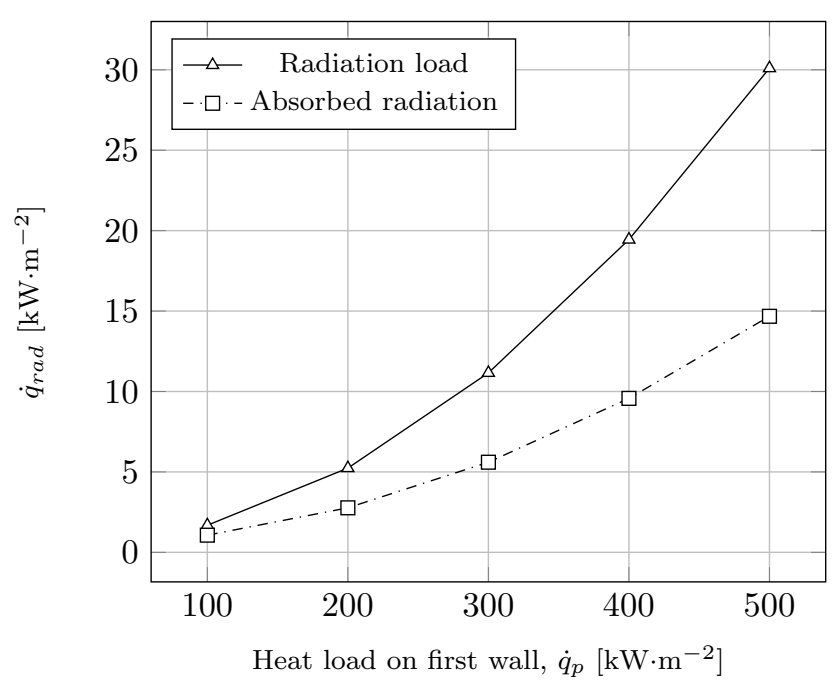

Figure 1: Emitted radiation from the backside of the first wall plus ECRH stray radiation and absorbed radiation on the plasma vessel.

between the first wall and the plasma vessel was done using the relation

$$
\dot{q}_{\text {rad }}=\frac{\sigma\left(T_{f w}^{4}-T_{P V}^{4}\right)}{\frac{1}{\epsilon_{f w}}+\frac{1}{\epsilon_{P V}}-1+\left(\frac{2}{\epsilon_{\text {shield }}}-1\right)}
$$

from literature [4]. The average backside temperature for the first wall was evaluated by taking the mean over the heat load portions emitted by the $\mathrm{Cu}-$ $\mathrm{CrZr}$ and graphite surfaces. This yields

$$
T_{f w}=\sqrt[4]{\frac{1}{\sigma \epsilon_{f w}} \cdot \frac{\sum\left(A_{i} T_{i}^{4}\right)}{\sum A_{i}}},
$$

where $\sigma$ is the Stefan-Boltzmann-constant and $\epsilon_{f w}$, the average emissivity of the backside. The fact that $85 \%$ of the emitted heat originates from the graphite tiles is taken into account by an emissivity of $\epsilon_{f w}=0.9$ for the first wall. The average temperature for the highly loaded first wall backside is then $T_{f w, 500}=590{ }^{\circ} \mathrm{C}$, whereas for the normally loaded tiles the temperature evaluates to $T_{f w, 250}=345{ }^{\circ} \mathrm{C}$. The plasma vessel temperature was assumed to be 

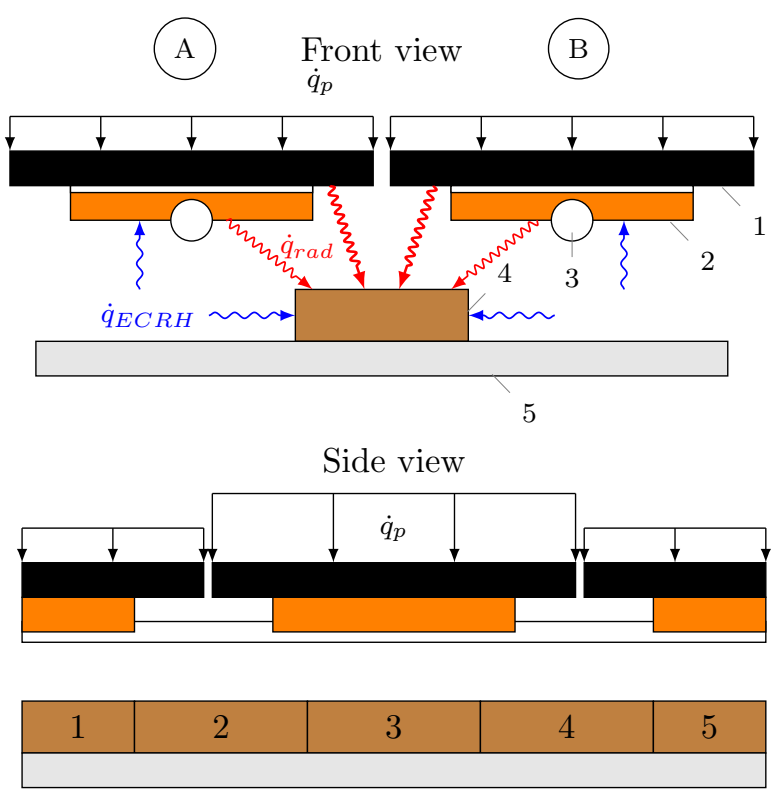

Figure 2: Cross section of the heat-shield area with subjacent diagnostics. top) (A) shows the situation without additional protection: Heat loads $\left(\dot{q}_{p}\right)$ from the plasma hit the heat-shield. The heat diffuses through the graphite tiles (1) into the $\mathrm{CuCrZr}$ heat sink (2), both connected via a $1 \mathrm{~mm}$ thick Sigraflex ${ }^{\circledR}$ layer in between. Heat is then absorbed by the water cooling (3). Diagnostics (4) are heated by thermal radiation $\left(\dot{q}_{r a d}\right)$ from the backside of the first wall and EC-stray radiation $\left(\dot{q}_{E C R H}\right)$. The same applies for the Plasma Vessel (5). bottom) The side view shows the segments of the Diamagnetic loop diagnostic below the first wall and the spatial distribution of the peak load in poloidal direction.
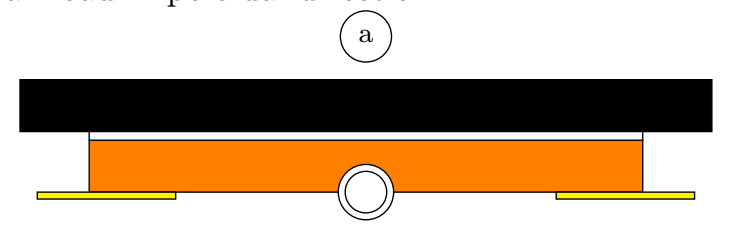

(b)

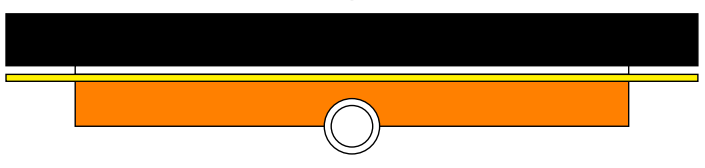

(c)

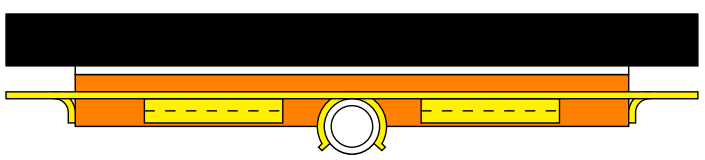

Figure 3: Options for the radiation shield below the first wall tiles. a) A Cu-shield mounted on the bottom side of the $\mathrm{CuCrZr}$ heat sink. b) $\mathrm{Cu}$-sheet installed below the first wall tile and before $\mathrm{CuCrZr}$.
$T_{P V}=60{ }^{\circ} \mathrm{C}$ with an emissivity of $\epsilon_{P V}=0.5$. These numbers show the dependency of the backside temperature on the $A_{\text {Graphite }} / A_{C u C r Z r}$ ratio (c.f. [5]).

The heat loads for a $2 \times 3$ tile array of the first wall were also evaluated. It was obtained by $\dot{q}_{\text {rad,array }}=$ $\left(2 \dot{q}_{\text {rad,250 }}+\dot{q}_{\text {rad,500 }}\right) / 3$ because it consists of two highly loaded tiles and four normally loaded tiles. It turned out that a Sigraflex ${ }^{\circledR}$-layer was not worth to be considered further. As listed in Table 1 it reduces the radiation heat flux density only by $40 \%$, whereas an ideal $\mathrm{Cu}$-shield reduces the heat flux density by $70 \%$. Subsequently only a $\mathrm{Cu}$-shield was considered. The estimate is conservative since the $\mathrm{Cu}$-shields as discussed in the following sections are contacted to the heat sink which reduces the heat flux further.

\begin{tabular}{lccc} 
Option & $\begin{array}{c}\dot{q}_{\text {rad,500 }} \\
{\left[\mathrm{kW} \cdot \mathrm{m}^{-2}\right]}\end{array}$ & $\begin{array}{c}\dot{q}_{\text {rad,250 }} \\
{\left[\mathrm{kW} \cdot \mathrm{m}^{-2}\right]}\end{array}$ & $\begin{array}{c}\dot{q}_{\text {rad,array }} \\
{\left[\mathrm{kW} \cdot \mathrm{m}^{-2}\right]}\end{array}$ \\
\hline Unprotected & 14.8 & 3.6 & 7.3 \\
Sigraflex ${ }^{\circledR}$-layer & 9.4 & 2.3 & 4.6 \\
Cu-shield & 4.5 & 1.1 & 2.2 \\
\hline
\end{tabular}

Table 1: Estimated radiative heat flux density for highly loaded first wall tiles $\left(\dot{q}_{\text {rad,500 }}\right)$ and normally loaded tiles $\left(\dot{q}_{r a d, 250}\right)$. The last column gives an estimation for the section of the later presented 3D model where highly and normally loaded tiles are considered in a $2 \times 3$ array.

\section{Detailed investigation of the chosen concept}

\subsection{Design options}

Three copper shield options are discussed in more detail: a) $\mathrm{Cu}$-sheet either bolted below the heat sink or b) inserted between graphite tile and $\mathrm{CuCrZr}$ heat sink or c) a $\mathrm{Cu}$-shield which is clamped onto the pipes, completely surrounding and touching the heat sink (see Figure 3). Detailed models of all versions were analyzed with FEA.

The thickness of the Cu-shield is $0.5 \mathrm{~mm}$. Emis- 
sivities for stainless steel (ss) and $\mathrm{CuCrZr}$ were assumed to be $\epsilon_{s s}=0.5$, for copper $\epsilon_{C u}=0.35$ and for graphite $\epsilon_{G}=0.9$. The ECRH absorbances are taken as $\alpha_{s s}=1 \%, \alpha_{C u C r Z r}=2 \%, \alpha_{G}=5 \%$ and $\alpha_{C u}=0.3 \%$ [9]. All models are built up on top of a $250 \times 150 \mathrm{~mm}$ wide portion of the plasma vessel. Five segments of the Diamagnetic-loop connected via copper stripes to the plasma vessel, are considered in options $a$ and $b$. The first wall is represented by six tiles, arranged in a $2 \times 3$ array. The center tiles were loaded with $500 \mathrm{~kW} \cdot \mathrm{m}^{-2}$, whereas the remaining tiles with $250 \mathrm{~kW} \cdot \mathrm{m}^{-2}$ (see Figure Figure 4). An ECRH load of $50 \mathrm{~kW} \cdot \mathrm{m}^{-2}$ was applied to all surfaces.

\subsection{Parametric studies}

The exact radiative material properties and their change during future machine operation are unknown. The main mechanism influencing the radiation characteristics is carbon dust deposition. Studies on other machines showed that carbon dust deposition depends on the location within the plasma vessel and the distance from the plasma [7]. Dependencies of the surface reflectivity on the thickness of the carbon deposited layer make it even more uncertain [8]. Thus the full range of possible reflectance degradation for stainless steel was investigated (see Table 2). The same degradation was assumed for $\mathrm{Cu}-$ $\mathrm{CrZr}$ which is the dominating material at the backside of the first wall. Copper emissivity and stainless steel emissivities were varied within a similar relative range. The microwave absorption properties were varied within the limits of known uncertainties [9]. However, the large parameter range is no major concern because the contribution to the overall heat balance remains small.

\section{Results}

The installation of a Cu-shield significatnly decreases temperatures in subjacent diagnostics. In the example of the Diamagnetic loop the temperature drops from $330{ }^{\circ} \mathrm{C}$ to around $160{ }^{\circ} \mathrm{C}$ for the bolted $\mathrm{Cu}$-shield (a) and for the $\mathrm{Cu}$-sheet in between the tile and $\mathrm{Cu}$ CrZr $(b)$. The variation in the temperature of the diagnostics over the different options is small.

The radiative heat fluxes onto the plasma vessel were calculated for options $a$ and $b$ with the Diamanetic loop present, for option $c$ without. The Diamanetic loop has only little influence on the plasma vessel load. Heat fluxes are reduced by a factor of about two with a bolted $\mathrm{Cu}$-shield. A factor of around 2.5 can be reached for the two other options (see Figure 5). The lower efficiency of option $a$ can be explained by the necessarily smaller shield dimensions which result in larger gaps for plasma radiation. Result details are given in Table 3. Remaining cumulative heat fluxes, from thermal and ECRH stray radiation with or without conductive terms from diagnostics, still persist on a level which is at the design limit. With the assumed level of ECRH absorption for the plasma vessel, one obtains values slightly above to $2 \mathrm{~kW} \cdot \mathrm{m}^{-2}$ (see Table 3 ).

From variation of the radiative properties $\epsilon$ and $\alpha$ a $\Delta T$ of around $50 \mathrm{~K}$ for the plasma vessel temperature and $70 \mathrm{~K}$ for the diagnostics was obtained (see Figure 6). Since the radiative loads on the components and the plasma vessel are the highest for the bolted $\mathrm{Cu}$-shield, it can be concluded that $\Delta T$ for the other options is smaller.

\section{Conclusions}

Simple estimations of heat fluxes from the first wall to the plasma vessel showed the benefit of an additional $\mathrm{Cu}$-shield behind the first wall. Accurate FEA calculations, considering thermal contact between the $\mathrm{Cu}$ shield and $\mathrm{CuCrZr}$ heat sink, confirmed the suitablity of options $b(\mathrm{Cu}$-sheet between graphite tile and the $\mathrm{CuCrZr})$ and $c$ (Cu-shield surrounding and touching the heat sink). The radiation load on plasma vessel and diagnostics can be reduced by an amount of $70 \%$ or more.

As a consequence, the temperatures of the diagnostics can be kept at about $170{ }^{\circ} \mathrm{C}$, well below their limit of $250{ }^{\circ} \mathrm{C}$. Furthermore, it was demonstrated that possible temperature variations, based on different material properties and carbon deposition, cause temperature variations of about $70 \mathrm{~K}$, which still leaves margins for diagnostic components. 


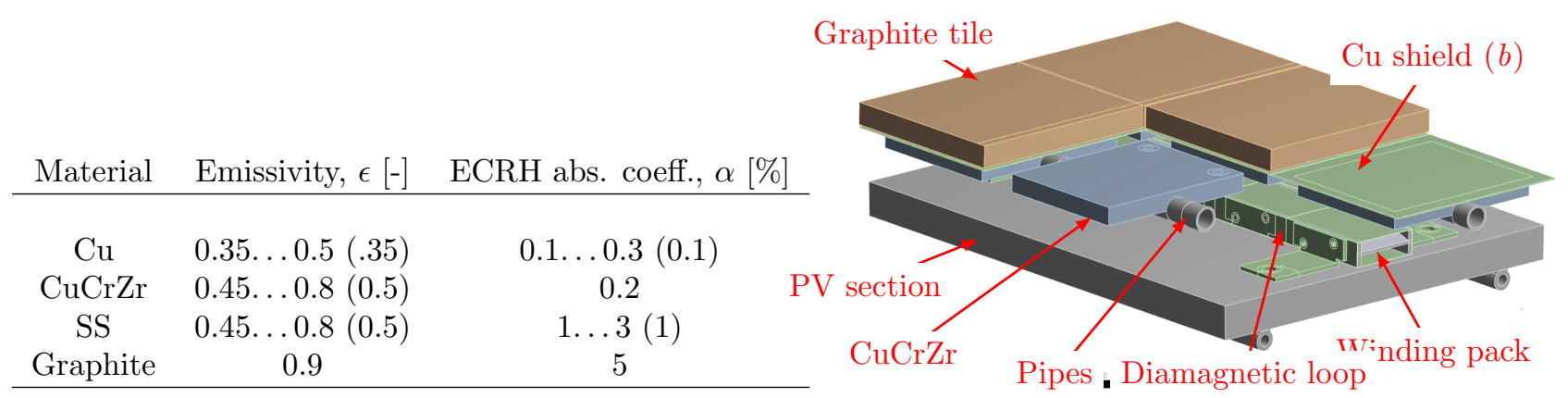

Table 2: Ranges for the parametric studies of the radiative properties. Standard values are noted in brackets.

Figure 4: 3D model of design option $b$ for the calculation of the heat flux density.

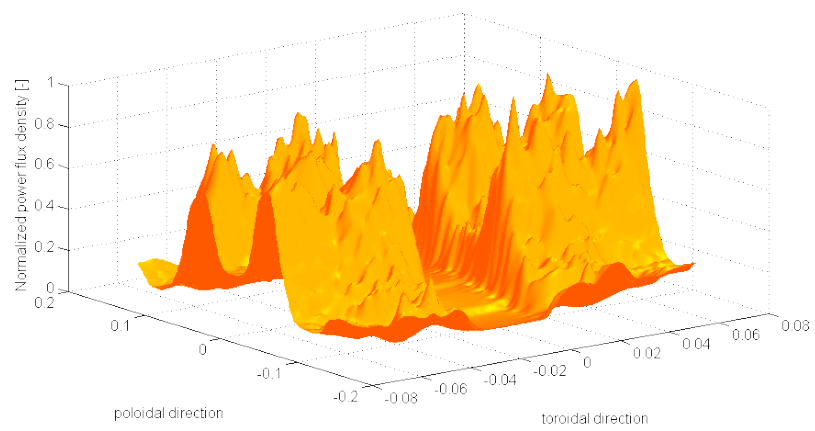

\begin{tabular}{ccccc} 
Option & $\dot{q}_{\text {rad }}$ & $\dot{q}_{c}$ & $\dot{q}_{E C R H}$ & $\begin{array}{c}\dot{q}_{\text {tot }} \\
{\left[\mathrm{kW} \cdot \mathrm{m}^{-2}\right]}\end{array}$ \\
\hline unprot. & 2.94 & 1.36 & 0.5 & 4.8 \\
$a$ & 2.0 & 0.67 & 0.5 & 3.2 \\
$b$ & 1.15 & 0.75 & 0.5 & $\mathbf{2 . 4}$ \\
$c$ & 1.7 & - & 0.5 & $\mathbf{2 . 2}$ \\
\hline
\end{tabular}

Table 3: Cumulative heat fluxes on the plasma vessel for the detailed analysed options with standard values for $\epsilon$ and $\alpha$. $\dot{q}_{t o t}$ is the cumulative heat flux onto the plasma vessel, resulting from thermal conduction $\left(\dot{q}_{c}\right)$ through attached diagnostics, net radiation $\left(\dot{q}_{\text {rad }}\right)$ from the heat shield and ECRH stray radiation $\left(\dot{q}_{E C R H}\right)$. The diagnostics were not considered in the analysis of type $c$.

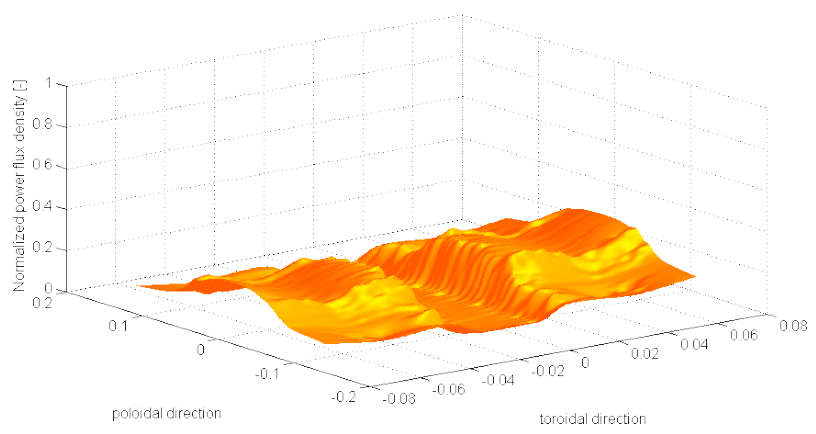

Figure 5: top) Normalized radiation heat flux density distribution for a section of the plasma vessel without shielding. Well to see is the Diamanetic loop in the center, shielding the vessel surface partially. To the left and right of the Diamanetic loop the slits between the heat shield section are good to identify, resulting in stretched peaks of incoming radiation. Sharp peaks arise from the discretization of the $3 \mathrm{~d}-$ model. The heat flux density is normalized to the 5 peak value of the unshielded portion. bottom) Radiation heat flux density distribution for design option $b$. The radiation through the slits disappears and only the part from the hot backside is left over. 


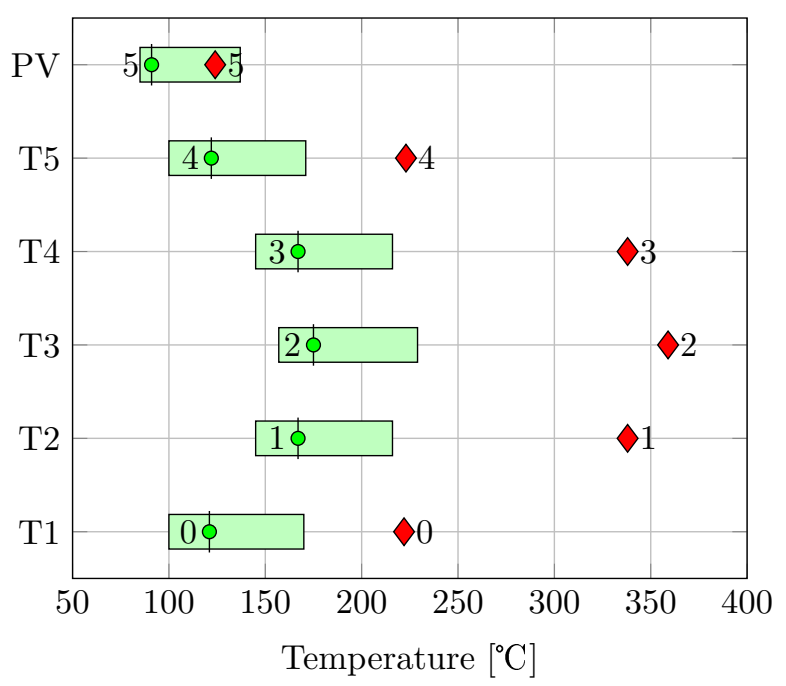

Figure 6: Bar plot of the calculated temperature ranges for option $a$. Temperature ranges for various segments of the Diamagnetic loop (T1, ..,T5, see Figure 2) and the plasma vessel (PV). Circles with a vertical bar indicate the standard values. Diamonds show the calculated temperatures for an unprotected Diamagnetic loop.

Not fully satisfying is the reduction of heat loads with respect to the plasma vessel, where with $2.2 \mathrm{~kW} \cdot \mathrm{m}^{-2}$ the design value is surpassed by about $10 \%$. However, considering the conservative assumptions and the small hot spot extensions the result is still acceptable.

The shield options $b$ and $c$ are thus suitable choices for the solution of the problem.

\section{References}

[1] H. Greuner, et. al., Concepts and prototype elements of the low- $\mathrm{Z}$ wall protection for the stellarator W7-X, Fus. Eng. and Des., Volumes 5657 (2001) 297-302

[2] R. Stadler, et. al., The in-vessel components of the experiment WENDELSTEIN 7-X, Fus. Eng. and Des., Volume 84, Issues 2-6 (2009) 305-308
[3] D. Hathiramani, et al., Fus. Eng. and Des., this conference

[4] H.D. Baehr, K. Stephan, Wärme- und Stoffübertragung, Springer-Verlag, Berlin, 1998

[5] X.B. Peng, et. al., Thermo-mechanical analysis of Wendelstein 7-X plasma facing components, Fus. Eng. and Des., this conference

[6] M. Nagel, et. al., Thermal and structural analysis of the W7-X magnet heat radiation shield, Fus. Eng. and Des., Volumes 75-79 (2005) 139142

[7] V.S. Voitsenya, A. Sagara, A.F. Bardamid, et al., et al., Effect of exposure inside the LHD vessel on reflectance of stainless steel mirrors, Problems of Atomic Science and Technology. (2002) "Plasma Physics" \#5(8) 39-41

[8] K.Yu. Vukolov, et al., The deposition of contaminants on the in-vessel mirrors in T-10 tokamak, ECA Vol.28G, (2004)

[9] H. Laqua, Spezifikation für Mikrowellenstreustrahlung in W7-X, 1-CBD20-S0001.2, internal report (2010) 